\title{
ANÁLISES DAS EXPERIÊNCIAS DE EDUCAÇÃO PATRIMONIAL NO ENSINO DE HISTÓRIA PELOS ESTUDANTES DAS ESCOLAS EREM PORTO DIGITAL E EREM PAULISTA (PERNAMBUCO/ BRASIL)
}

\author{
Isabela Nathália Nunes Tristão \\ Programa de Pós-Graduação em Educação \\ Universidade Federal da Paraíba \\ tristaoisabela@gmail.com \\ Adriana Maria Paulo da Silva \\ Universidade Federal de Pernambuco \\ adrianampsilva@gmail.com
}

\begin{abstract}
RESUMO
Resultado de um Trabalho de conclusão de curso, esta pesquisa emergiu de um conjunto de atividades vinculadas aos projetos "Retratos do Recife: século XX, memória e patrimônio" e "Tecelões da memória operária: a História do Paulista didatizada" e desenvolvidas por bolsistas do Programa Institucional e Bolsa de Iniciação à Docência (PIBID-História) da Universidade Federal de Pernambuco, nos anos de 2014 e 2015, em duas escolas estaduais de referência do ensino médio: EREM Porto Digital (localizada no Recife Antigo/ PE) e EREM Paulista (no bairro da Torres Galvão/ PE), respectivamente, cujo objetivo foi vivenciar a Educação Patrimonial através do estudo da História Local. Dos resultados dos referidos projetos, aprofundamos a temática em questão, por intermédio de entrevistas feitas a grupos de estudantes das duas ditas escolas- metodologia de grupo focal- com o objetivo de analisar as experiências de Educação Patrimonial na vida dos entrevistados. Percebemos que, de maneira geral, as atividades com Educação Patrimonial geraram um sentimento de pertencimento e uma ampliação de conhecimentos históricos, sociais e culturais sobre os bairros estudados.
\end{abstract}

Palavras-chave: Ensino de História. Educação Patrimonial. História Local.

\section{ANALYSIS OF THE EXPERIENCES OF HERITAGE EDUCATION IN THE EDUCATION OF HISTORY BY STUDENTS OF THE EREM DIGITAL AND EREM PAULISTA SCHOOLS (PERNAMBUCO / BRAZIL)}

\begin{abstract}
The result of a work of completion of course, this research emerged from a set of activities linked to the projects "portraits of the Recife: twentieth century, Memory and heritage" and "weavers of the working memory: The History of Paulista Didatized" and developed by Scholarship holders of the institutional program and scholarships for initiation to teaching (PIBID-History) of the Federal Universtity of Pernambuco, in the years 2014 and 2015, in two state schools of high School reference: EREM Porto Digital (located in Recife /PE) and EREM Paulista (in the neighborhood of Torres Galvão/PE), respectively, whose objective was to experience the Patrimonial education
\end{abstract}

Rev. Iberoam. Patrim. Histórico-Educativo, Campinas (SP), v. 5, p. 1-30, e019027, 2019. 
through the study of Local history. From the results of these projects, we deepen the theme in question, through interviews made to groups of students of the two said schools - focus group methodology - with the objective of analyzing the experiences of Patrimonial education in life of the interviewees. We realized that, in general, activities with Patrimonial education generated a sense of belonging and an expansion of historical, social and cultural knowledge about the neighborhoods studied.

Keywords: History Teaching. Heritage Education. Local history.

\section{ANÁLISIS DE LAS EXPERIENCIAS DE EDUCACIÓN PATRIMONIAL EN LA ENSEÑANZA DE HISTORIA POR LOS ESTUDIANTES DE LAS ESCUELAS EREM PORTO DIGITAL Y EREM PAULISTA (PERNAMBUCO / BRASIL)}

\section{RESUMEN}

Fruto de una obra de terminación de curso, esta investigación surgió de un conjunto de actividades vinculadas a los proyectos "Retratos del arrecife: siglo XX, memoria y patrimonio" y "tejedores de la memoria de trabajo: la historia de la Didatizada Paulista" y desarrolladas por Becados del programa institucional y becas de iniciación a la docencia (PIBID-história) de la Universidade Federal de Pernambuco, en los años 2014 y 2015, en dos escuelas estatales de referencia de la escuela secundaria: EREM Porto digital (ubicada en Recife Antigo/PE) y EREM Paulista (en el barrio de Torres Galvão/PE), respectivamente, cuyo objetivo era experimentar la educación patrimonial a través del estudio de la historia local. A partir de los resultados de estos proyectos, profundizamos el tema en cuestión, a través de entrevistas realizadas a grupos de estudiantes de las dos dichas escuelas - metodología de grupo de enfoque - con el objetivo de analizar las experiencias de la educación patrimonial en la vida de los entrevistados. Nos dimos cuenta de que, en general, las actividades con la educación patrimonial generaron un sentimiento de pertenencia y una expansión del conocimiento histórico, social y cultural sobre los barrios estudiados.

Palabras clave: enseñanza de historia. Educación patrimonial. La historia local.

\section{ANALYSE DES EXPÉRIENCES DE L'ÉDUCATION PATRIMONIALE DANS L'ENSEIGNEMENT DE L'HISTOIRE PAR LES ÉTUDIANTS DES ÉCOLES EREM PORTO DIGITAL ET EREM PAULISTA (PERNAMBUCO/BRÉSIL)}

\section{RÉSUMÉ}

Résultat d'un travail d'achèvement bien sûr, cette recherche a émergé d'un ensemble d'activités liées aux projets "Portraits du récif: XXe siècle, mémoire et patrimoine" et "tisserands de la mémoire de travail: l'histoire de Paulista Didatizada" et développé par Les boursiers du programme institutionnel et les bourses d'initiation à l'enseignement (PIBID-História) de l'Universidade Fédéral de Pernambuco, dans les années 2014 et 2015, dans deux écoles publiques de référence du secondaire: EREM Porto Digital (situé à Recife Antigo/PE) et EREM Paulista (dans le quartier de Torres Galvão/PE), respectivement, dont l'objectif était de faire l'expérience de l'éducation patrimoniale par le biais de l'étude de l'histoire locale. À partir des résultats de ces projets, nous approfondissons le thème en question, à travers des interviews faites à des groupes d'étudiants de

Rev. Iberoam. Patrim. Histórico-Educativo, Campinas (SP), v. 5, p. 1-30, e019027, 2019. 
ces deux écoles-méthodologie de groupe de discussion-avec l'objectif d'analyser les expériences de l'éducation patrimoniale dans la vie des interviewés. Nous avons réalisé que, en général, les activités avec l'éducation patrimoniale ont généré un sentiment d'appartenance et une expansion des connaissances historiques, sociales et culturelles sur les quartiers étudiés.

Mots-clés: enseignement de l'histoire. L'éducation patrimoniale. Histoire locale.

\section{INTRODUÇÃO}

O Programa Institucional de Bolsa de Iniciação à Docência (PIBID) em História da UFPE ${ }^{1}$ iniciou-se com o edital de 2014, com o quantitativo de 25 bolsistas, distribuídos em cinco escolas localizadas em diferentes bairros do Recife/ Pernambuco. Alicerçado em três pilares educacionais - Ensino, Pesquisa e Extensão, ligando a Universidade às escolas públicas da Região Metropolitana do Recife e os seus entornos - o Programa apresenta como diretrizes uma formação inicial completa e qualificada para os estudantes de licenciatura, a formação continuada de professores e professoras das escolas públicas parceiras e a busca por novas metodologias ativas e inovadoras nos ambientes escolares (FREIRE; RAMOS; DIONISIO, 2014).

Foram realizados dois projetos de pesquisa/ensino, intitulados "Retratos do Recife: Século XX, memória e patrimônio" e "Tecelões da memória operária: a História do Paulista didatizada", desenvolvidos por 05 bolsistas atuantes no PIBID, em diferentes momentos, na escola de referência em Ensino Médio Porto Digital (localizada no bairro do Recife Antigo) e na Escola Estadual Do Paulista (atual EREM Paulista, no bairro da Torres Galvão), nos anos de 2014 e 2015, cujo objetivo foi promover a vivência da Educação Patrimonial através do estudo da História Local. Este objetivo foi traçado por orientação das professoras coordenadoras do PIBID $^{2}$ para todos os grupos atuantes, em diferentes bairros, e foi planejado com base na constatação, durante a fase de observação das escolas-campo, da existência de um distanciamento dos estudantes das escolas da disciplina História e das histórias dos bairros nos quais as escolas se localizavam.

\footnotetext{
${ }^{1}$ Disponível em: https://www.facebook.com/pibidhistoriaufpe/ Disponível em: http://pibidhistoriaufpe.blogspot.com.br/

${ }^{2}$ Nos períodos e planejamento e execução de ambos projetos, o PIBID foi coordenado não apenas pela Professor Dr ${ }^{\mathrm{a}}$ Adriana Maria Paulo da Silva (http://lattes.cnpq.br/6190925965820163), como também pela Professora Dr ${ }^{\mathrm{a}}$ Isabel Cristina Martins Guillen (http://lattes.cnpq.br/8822901286294537).
}

Rev. Iberoam. Patrim. Histórico-Educativo, Campinas (SP), v. 5, p. 1-30, e019027, 2019. 
Na etapa de planejamento das aulas, utilizamos o 'Guia Básico de Educação Patrimonial', desenvolvido pelo Instituto do Patrimônio Histórico e Artístico Nacional (HORTA; GRUNBERG; MONTEIRO, 1999), o qual sugere quatro etapas para o desenvolvimento do trabalho em Educação Patrimonial:

- Observação: na qual deve haver um "desenvolvimento da percepção visual e simbólica" por parte dos estudantes;

- Registro: "aprofundamento e fixação do conhecimento percebido" por parte dos estudantes;

- Exploração: análises, discussões, pesquisas, interpretações e avaliações realizadas pelos estudantes, por intermédio das proposições do docente/educador;

- Apropriação: participação criativa, valorização e aproximação pessoal dos estudantes junto aos bens estudados.

As quatro etapas acima auxiliaram as atividades desenvolvidas nas duas escolas estaduais, os quais se direcionaram para ênfase em conteúdos que dialogassem com a dinâmica e complexidade social dos espaços de vivências dos estudantes, com o intuito de apresentá-los e sensibilizá-los às mudanças e continuidades históricas na paisagem urbana das suas cidades.

O primeiro projeto, intitulado "Retratos do Recife: Século XX, Memória e Patrimônio", executou atividades didáticas objetivando a operacionalização do conceito de "patrimônio", a análise da historicidade de alguns patrimônios da cidade do Recife e sua caracterização geográfica. Trabalhamos, através de aulas e atividades de campo, com lugares de memória do Recife considerados "centrais" pelos estudantes, tais como: a Avenida Rio Branco, o centenário Mercado de São José e a Praça da República, localizados em dois dos bairros centrais do Recife: Santo Antônio e São José.

Visitamos os arquivos da Fundação Joaquim Nabuco (FUNDAJ) e ao Museu do Estado de Pernambuco (MEPE), com objetivo identificarmos diferentes tipos de registros documentais disponíveis sobre o bairro do Recife. Ao término das atividades do Projeto, promovemos, junto à comunidade escolar, uma exposição do material fotográfico e textual elaborado, à luz das "fontes" obtidas nas instituições de guarda visitadas pelos (as) estudantes envolvidos nas ações empreendidas. 
O segundo projeto, intitulado "Tecelões da Memória Operária: a História do Paulista didatizada", foi desenvolvido objetivando estudar a Educação Patrimonial através do estudo da História Local, utilizando a metodologia da História Oral como uma ferramenta e fonte historiográfica. Na primeira etapa, a execução do projeto realizou nas aulas de história regidas pelos bolsistas, os quais promoveram estratégias para a identificação, localização e historicização de alguns bens materiais e imateriais constitutivos da cidade do Paulista, por parte dos (as) estudantes. Na segunda etapa, foram realizadas oficinas de história, utilizando os procedimentos da metodologia da História Oral e a análise de fotografias da cidade, as quais indicaram a centralidade dos operários na Companhia de Tecidos do Paulista na formação e desenvolvimento da dita cidade.

O desenvolvimento dos projetos acima impulsionou-nos a aprofundar, neste trabalho, a forma como as ações/atividades desenvolvidas foram vivenciadas pelos alunos da EREM Porto Digital e da EREM Paulista, por intermédio da metodologia do grupo focal. Observaremos a relevância (ou não) das experiências com Educação Patrimonial na vida dos estudantes, analisando as aprendizagens e percepções construídas e/ ou reconstruídas durante e depois das ações do PIBID-História/UFPE nas escolas, por meio do recurso do grupo focal realizadas com dois grupos de estudantes.

Mediante a metodologia do grupo focal (GATTI, 2005), refletimos criticamente sobre as dicotomias existentes entre os saberes acadêmicos e os saberes escolares ${ }^{3}$, integrando, de forma didática e elaborada, os estudantes, as escolas e os bairros nos quais estão inseridos. Faremos, inicialmente, um debate sobre os conceitos de Patrimônio, Educação Patrimonial e História Local, apontando questões relacionadas ao ensino de História. Posteriormente, descreveremos e explicaremos as potencialidades do ensino de História no PIBID/ HISTÓRIA da UFPE, através das atividades desenvolvidas e vinculadas aos dois projetos em questão, durante os anos de 2014 e 2015. Por último, analisaremos as falas dos estudantes entrevistados, articulando-as com as leituras realizadas e conceitos analisados, bem como focalizaremos as experiências de Educação Patrimonial vivenciadas pelos (as) estudantes envolvidos (as) nestes projetos. Acreditamos que a

${ }^{3}$ Concordamos que o conhecimento histórico escolar não deve ser compreendido como mera e simples transposição de um conhecimento maior, acadêmico, que é simplificado pelo Ensino Fundamental ou médio (BARBOSA, 2006).

Rev. Iberoam. Patrim. Histórico-Educativo, Campinas (SP), v. 5, p. 1-30, e019027, 2019. 
construção de cidades mais solidárias e humanas depende, em larga medida, da promoção de atividades escolares deste tipo (TRISTÃO; SILVA, 2017).

\section{EDUCAÇÃO PATRIMONIAL E HISTÓRIA LOCAL: ABORDAGENS CONCEITUAIS}

Advinda do vocábulo de origem latina - pater-a definição conceitual de patrimônio remete, inicialmente, à herança transmitida do patriarca aos seus descendentes. No entanto, o patrimônio não está associado apenas aos bens que recebemos ou herdamos das nossas famílias, mas também a bens históricos e culturais (muitos, imateriais) legados, em nossas sociedades, pelas gerações que nos antecederam ${ }^{4}$. Nas aulas de História trabalhamos para a compreensão e problematização das nossas heranças socioculturais no Brasil, o órgão governamental responsável pelo patrimônio é o IPHAN (Instituto do Patrimônio Histórico e Artístico Nacional), instituído através do SPHAN (Serviço do Patrimônio Histórico e Artístico Nacional), criado em 1936, durante o governo de Getúlio Vargas. De acordo com Fonseca (2003, p. 59-60), a Constituição Federal de 1988, o artigo 216 define como patrimônio cultural brasileiro, os bens materiais e imateriais que referenciam as identidades, as ações e as memórias dos diferentes grupos que compõem a sociedade brasileira, nos quais se incluem:

I. $\quad$ as formas de expressão;

II. os modos de criar, fazer e viver;

III. as criações científicas, artísticas e tecnológicas;

IV. as obras, objetos, documentos, edificações e demais espaços destinados às manifestações artístico-culturais;

V. os conjuntos urbanos e sítios de valor histórico, paisagístico, artístico, arqueológico, paleontológico, ecológico e científico.

Desde o final do século XX, houve uma intensificação nas discussões em torno dos significados políticos e culturais da preservação do patrimônio cultural. O IPHAN, considerado o "guardião legal do patrimônio histórico e artístico nacional" (FONSECA, 1997), tem sido sujeito e objeto de estudo de importantes trabalhos. Maria Cecília Londres Fonseca (1997), por exemplo,

${ }^{4}$ De acordo com Soares, "a concepção do patrimônio nasce na forma de herança de caráter cultural, mas também, econômica. A compreensão desta dubiedade é importante para traçar os (des) caminhos do patrimônio desde suas origens até sua transformação em bens culturais" (SOARES, 2009, p. 21).

Rev. Iberoam. Patrim. Histórico-Educativo, Campinas (SP), v. 5, p. 1-30, e019027, 2019. 
analisou uma multiplicidade de interesses que regeram as políticas de preservação deste órgão, bem como as tensões socioculturais entre uma política tradicional de preservação, dirigida por profissionais que privilegiavam o patrimônio de "pedra e cal”, e uma política mais plural e flexível, voltada para a grande heterogeneidade cultural, e consequentemente, patrimonial do país.

Acreditando nessa pluralidade e flexibilidade, entendemos o patrimônio como um “conjunto dos saberes, fazeres, expressões, práticas e seus produtos" (BRAYNER, 2007, p. 12), relacionados a diferentes histórias, memórias e identidades culturais. O patrimônio cultural, por sua vez,

Se manifesta como um conjunto de bens e valores, tangíveis e intangíveis, expressos em palavras, imagens, objetos, monumentos e sítios, ritos e celebrações, hábitos e atitudes, cuja manifestação é percebida por uma coletividade como uma "marca" que a identifica, que adquire um sentido "comum" e compartilhado por toda uma "comunidade". (HORTA, 2000, p. 29).

Compreendemos a Educação Patrimonial "[...] como um processo permanente e sistemático de trabalho educacional, centrado no patrimônio cultural como fonte primária de conhecimento e enriquecimento individual e coletivo" (HORTA, GRUNBERG; MONTEIRO, 1999, p. 06). Processo permanente e sistemático relacionado diretamente com os usos das memórias dos diferentes grupos sociais.

O termo "memória" remete, inicialmente, a um conjunto de funções psíquicas onde as pessoas podem atualizar informações passadas e se utilizar delas. Presente, principalmente, nos estudos da biologia, psiquiatria e psicologia, a memória está relacionada a aspectos de recordações e esquecimentos, através de manipulações conscientes ou inconscientes. Ela é um instrumento e um objeto de poder, que permite compreender lutas pela dominação e recordação de tradições. Conforme Jacques Le Goff, “A memória, onde cresce a história, que por sua vez a alimenta, procura salvar o passado para servir o presente e o futuro" (LE GOFF, 2013, p. 437). Pollak (1992), por sua vez, mostra os principais elementos constitutivos da memória, individual ou coletiva, destaca acontecimentos vividos pessoalmente e acontecimentos vividos pelo grupo ou pela coletividade à qual a pessoa se sente pertencer. Ou seja, “[...] é perfeitamente possível que, por meio da socialização política, ou da socialização histórica, ocorra um fenômeno de projeção ou de

Rev. Iberoam. Patrim. Histórico-Educativo, Campinas (SP), v. 5, p. 1-30, e019027, 2019. 
identificação com determinado passado, tão forte que podemos falar numa memória quase que herdada" (POLLAK, 1992, p. 201). Levando-se em consideração a nossa preocupação com os princípios e metodologias que favoreçam o ensino de História, tornando-o mais próximo e significativo para os estudantes da educação básica, consideramos necessário analisar as transformações que ocorreram e continuam ocorrendo na História enquanto disciplina, e as ações governamentais empreendidas em torno dos conteúdos de história difundidos nos ambientes escolares e suas relações com a inserção de propostas com Educação Patrimonial.

As orientações curriculares para o Ensino Médio ${ }^{5}$, por exemplo, buscando responder questões acerca de importância da História, afirmam que é através dela que nós (docentes) podemos ensinar os estudantes a analisar suas experiências de vida “[...] para identificarem as relações que essas guardam com experiências históricas de outros sujeitos em tempos, lugares e culturas diversas das suas" (BRASIL, 2006, p. 65). Para isto, destacam a importância de ajudar estudantes a (re) construírem um sentido para o estudo da História através de ações educativas bem articuladas.

A Lei de Diretrizes e Bases da Educação Nacional (Lei n 9.394/96), em seu Artigo 26, destaca a necessidade de se explorar e analisar as características regionais e locais das sociedades no que se refere a sua diversidade cultural.

No entanto, o ensino escolar da História é geralmente estruturado a partir de "tradições" sendo, atualmente, abordado nas escolas em uma perspectiva linear, constituída dentro dos marcos cronológicos da História Europeia: Idades Antiga, Média, Moderna e Contemporânea. Somandose ainda o fato das escolas priorizarem um viés quantificador de avaliação, como a verificação das quantidades de acertos nas provas; a imitação de mecanismos que possibilitem respostas corretas e o ato de decorar o que já foi ensinado, ou lido em algum livro, vemos que tal sistema educacional, muito difundido atualmente, foca na questão do máximo desempenho em menor tempo, levando os alunos a uma tendência tecnicista, cujo auge, no Brasil, decorreu da década de 1970 (FONSECA, 1993).

${ }^{5}$ Elaboradas pelo MEC (2006), discutem não apenas o currículo de História para o Ensino Médio e a importância desta disciplina na vida dos estudantes, como também os próprios conteúdos propostos (trabalho, cultura, memória, cidadania, etc.). De acordo com a versão em questão, seu objetivo principal é o de construir e apontar indicativos que possam fornecer possibilidades didático-pedagógicas para a organização do trabalho pedagógico, atendendo às necessidades e expectativas das escolas e dos professores (BRASIL, 2006).

Rev. Iberoam. Patrim. Histórico-Educativo, Campinas (SP), v. 5, p. 1-30, e019027, 2019. 
Com relação ao professor (a) de História, métodos tradicionais persistem. A introdução ao conteúdo de ensino e o próprio fazer pedagógico estão majoritariamente baseados em aulas expositivas - penas faladas e com uso do quadro -, centradas nos docentes e seus interesses, as quais servindo à transmissão de conhecimentos tidos como verídicos e inalteráveis. É possível que tal sistema também gere educandos pouco interessados na prática de investigação crítica ou mesmo na busca autônoma de informações. Dentro dessa perspectiva concordamos com Cabrini et al. (2000, p. 34) quando afirma que:

Essa história, que exclui a realidade do aluno, que despreza qualquer experiência da história por ele vivida, impossibilita-o de chegar a uma interrogação sobre sua própria historicidade, sobre a dimensão histórica de sua realidade individual, de sua família, de sua classe, de seu país, de seu tempo... Essa história torna "natural" o fato de o aluno não se ver como um agente histórico, torna-o incapaz de colocar questões ou de perceber os conhecimentos que, a partir de suas experiências individuais, possam ser a base de discussão em sala de aula.

A Educação Patrimonial abre uma possibilidade para inovação pedagógica dentro dos ambientes escolares, nos quais professores e alunos podem interagir em conjunto e didaticamente com seus espaços, práticas e produtos culturais de referência. A depender dos objetivos docentes, pode ser um processo contínuo de experimentação e descoberta, articulando conhecimento, apropriação e valorização das vivências socialmente compartilhadas. Articulada a potencialidade da Educação Patrimonial, precisamos ampliar a noção de bem patrimonial para lançar luzes sobre os aspectos cotidianos, corriqueiros, simples ou naturais das práticas e produtos culturais presentes nas vidas das pessoas comuns (TEXEIRA, 2008).

Nos Parâmetros Curriculares Nacionais (PCNs) ${ }^{6}$, a Educação Patrimonial assume uma perspectiva transversal e interdisciplinar, direcionada, em princípio, para o Ensino Fundamental. Os PCN's classificam como temas transversais alguns dos principais temas (merecedores de um tratamento interdisciplinar) que atravessam todas as práticas sociais atuais vividas por estudantes, tais como meio ambiente, ética, saúde, pluralidade cultural, orientação sexual, etc. Consideramos ser preciso pensar em estratégias de ampliação de conhecimentos, usos da interdisciplinaridade e,

\footnotetext{
${ }^{6}$ Os Parâmetros (ou Orientações) curriculares para o Ensino Fundamental (divididos em 04 ciclos) representam um importante instrumento de reflexão sobre a prática do ensino no Brasil. Seu papel principal, de acordo com a versão do texto publicada em 1998, pelo MEC, é dar subsídios às discussões e ao desenvolvimento de projetos educativos, às reflexões sobre a prática pedagógica, aos planejamentos de aulas e às seleções e análises de materiais didáticos que possam auxiliar na formação e atualização profissional (BRASIL, 1998).
}

Rev. Iberoam. Patrim. Histórico-Educativo, Campinas (SP), v. 5, p. 1-30, e019027, 2019. 
principalmente, dar condições para que os professores e professoras possam ter uma formação contínua, sempre atualizando seus saberes e práticas pedagógicas, uma vez que

Ambas - transversalidade e interdisciplinaridade - se fundamentam na crítica de uma concepção de conhecimento que toma a realidade como um conjunto de dados estáveis, sujeitos a um ato de conhecer isento e distanciado. Ambas apontam a complexidade do real e a necessidade de se considerar a teia de relações entre os seus diferentes e contraditórios aspectos. Mas diferem uma da outra, uma vez que a interdisciplinaridade refere-se a uma abordagem epistemológica dos objetos de conhecimento, enquanto a transversalidade diz respeito principalmente à dimensão da didática. (BRASIL, 1997, p. 31).

Entendemos a escola e os seus entornos como lugares privilegiados para articulação dos conhecimentos e vivências de professores e alunos. O ensino de História, pelo viés de articulação entre história local e educação patrimonial pode promover um redimensionamento entre o local e o global, ao deslocar a centralidade dos problemas discutidos e relacioná-los com os grupos sociais que fizeram e/ou continuam fazendo parte dos bairros do Recife e do Paulista. Para além do que é tido como "tradicional" nos ambientes escolares, acreditamos nos potenciais renovadores da Educação Patrimonial e da História Local na medida em que há possibilidades de professores e alunos ampliarem suas sensibilidades e conhecimentos a respeito do local onde vivem e de outros locais. Os sujeitos envolvidos no processo de ensino-aprendizagem sobre a história local perceberão que as suas realidades históricas, sociais e culturais não estão isoladas no mundo - não opondo história local de história global - mas fazem parte de um processo complexo de construção de identidades - sempre destacando as pluralidades e particularidades envolvidas, no âmbito do espaço social e temporal escolhido (CARVALHO, 2007, p. 54-55).

A partir das atividades empreendidas, entendemos que levar em conta os aspectos históricos e sociais dos bairros nos quais as escolas já mencionadas se localizam favorece um processo dinâmico e profundo de conhecimento. Os estudantes podem focalizar diferentes questões relevantes para si, seus grupos de origem, para o país e para o mundo relacionando-as. Com isso, no presente texto, a História Local é entendida como

Uma modalidade de estudos históricos que, ao operar em diferentes escalas de análises, contribui para a construção de processos interpretativos sobre as diferentes formas de como os atores sociais se constituem historicamente. Ou seja, interessa-se pelos modos de viver, coletivos e individuais, dos sujeitos e grupos sociais situados em espaços que são coletivamente construídos e representados, 
na contemporaneidade, pelo poder político e econômico, sob a forma estrutural de "bairros" e "cidades". (TOLEDO, 2010, p. 751).

As atividades focalizadas contaram com uma metodologia direcionada à experimentação ativa dos alunos participantes com os patrimônios materiais e imateriais dos seus bairros (SCHIAVON; SANTOS, 2011).

Objetivamos, de maneira geral, analisar diversos espaços do Recife e do Paulista, com base nos trabalhos com Educação Patrimonial e História Local, possibilitando a entrada de novas temáticas no currículo de História das Escolas de Referência em Ensino Médio Porto Digital e Paulista, respectivamente. E buscando entender as possíveis relevâncias que estes trabalhos apresentaram na vida dos estudantes, analisamos e problematizamos os diálogos travados com dois grupos focais diferentes - com características e vivências próprias. Foram dinâmicas contínuas e grupais, que geraram reflexões, análises, problematizações, engajamentos e novas possíveis propostas de trabalhos.

\section{O projeto "Retratos do Recife: século XX, memória e patrimônio" - EREM Porto Digital}

Localizada no bairro central do Recife/ Pernambuco, na Avenida Rio Branco, a Escola de Referência em Ensino Médio Porto Digital possui localização privilegiada e boa infraestrutura. Abrange turmas dos primeiros, segundos e terceiros anos do Ensino Médio e possui cerca de 361 estudantes e 33 professores ${ }^{7}$.

Nesta escola, as atividades aconteceram durante o ano letivo de 2014, no qual foram planejadas e executadas aulas de Educação Patrimonial, História, Geografia e Sociologia sobre a cidade do Recife, focalizando os três bairros centrais: bairros do Recife, Santo Antônio e São José. Levando-se em consideração que o bairro do Recife, atualmente, se configura como um bairro comercial e os estudantes não residem no mesmo, tivemos como objetivo principal sensibilizar os estudantes para as rupturas e continuidades históricas na paisagem urbana da cidade do Recife, destacando a importância do reconhecimento, valorização e conservação desse patrimônio sobrevivente em meio a intensa modernização dos espaços urbanos - juntamente com a criação de

\footnotetext{
7 Informação retirada do Portal SIEPE (Sistema de Informações da Educação de Pernambuco). Disponível em: http://www.siepe.educacao.pe.gov.br/MapaCoordenadoria/detEscola.do?codUnidade=606264. Acesso em 07 jun. 2019.
} 
laços de solidariedade entre as suas gentes e os (as) estudantes da escola campo. Foram discutidos os aspectos geográficos e as dinâmicas sociais de ocupação desses espaços, ao visitarmos três importantes localidades do bairro em questão: Mercado de São José, Praça da República e Avenida Rio Branco $^{8}$.

Inicialmente, no período de observação (HORTA; GRUNBERG; MONTEIRO, 1999), percebemos que, os estudantes conheciam muito precariamente o bairro e os seus entornos. Foi com base nesse distanciamento dos estudantes com a historicidade do bairro que elaboramos cinco aulas iniciais, aportadas em fontes iconográficas (MAUAD, 1996) relativos às principais mudanças urbanísticas vivenciadas pela cidade.

As duas primeiras aulas se direcionaram para a discussão e apropriação do conceito de patrimônio e as outras três aulas trataram dos bens patrimoniais existentes (e publicamente reconhecidos) a serem visitados, mais especificamente.

Com participação facultativa, engajaram-se no projeto 27 alunos dos $1^{\mathrm{a}}$ e $2^{\mathrm{a}}$ anos, divididos em quatro equipes, as quais intitularam-se: "Armorial", "Beberibe", "Capibaribe" e "Manguebeat" - nomes definidos pelos próprios estudantes. Em paralelo com o período das aulas, visitamos as instituições de guarda (Fundação Joaquim Nabuco e Museu do Estado de Pernambuco). Nestas visitas, observamos algumas fotografias que nos ajudaram a conhecer a narrativa da exposição permanente a respeito da história de Pernambuco.

Também tivemos a oportunidade de participar da VII Semana do Patrimônio Cultural de Pernambuco - fruto da parceria entre a Secretaria de Cultura do Estado de Pernambuco (Secult) e a Fundação do Patrimônio Histórico e Artístico de Pernambuco (Fundarpe). Guiados por instrutores Secult, o grupo de estudantes teve como roteiro a Rua da Alfândega, Rua Marquês de Olinda, Praça do Marco Zero e a Praça do Arsenal. A cada local visitado, o grupo foi apresentado aos estilos arquitetônicos predominantes nas ruas do Bairro do Recife, em sua dinâmica de transformações, marcantes no século XX. Ou seja, a caminhada ofereceu uma perspectiva histórica sobre os pontos históricos recifenses, não vivenciada anteriormente pelos estudantes.

${ }^{8}$ Para maiores detalhes sobre as atividades, ler também: TRISTÃO, I. N. N.; RIBEIRO, A. A. M.; QUEIROZ, G. F. S.; SILVA, A. M. P. Retratos do Recife: Século XX, memória e patrimônio. In: XI Seminário de Iniciação à Docência, 2014, Natal. Professores em espaços de formação: mediações, práxis e saberes docentes, 2014.

Rev. Iberoam. Patrim. Histórico-Educativo, Campinas (SP), v. 5, p. 1-30, e019027, 2019. 
Após estas etapas, iniciamos as "aulas de campo", acompanhados não apenas do Professor Supervisor ${ }^{9}$, como também de professores de outras disciplinas, como Geografia e Sociologia.

Como primeira atividade de campo, visitamos o Mercado de São José, localizado na Praça Dom Vital, no Bairro de São José, o qual sintetizou, durante o século XIX, os "ideais de modernidade, salubridade e civilidade discutidos e aspirados pela elite" (GUILLEN; GRILLO; FARIAS, 2010, p. 10). Articulada às discussões acerca da historicidade e da importância do Mercado como patrimônio da cultura nacional, destacamos a dinâmica de transformações ocorridas no ambiente no qual o Mercado está inserido.

Inaugurado em 1875, o Mercado fora construído no espaço anteriormente ocupado pela tradicional Ribeira do Peixe, importante feira de produtos alimentícios da cidade desde século XVIII. À época, as atividades dos comerciantes de peixe divergiam da perspectiva de modernização do Recife do século XIX, profundamente marcado pelo discurso higienista e pelas denúncias de insalubridade no espaço urbano. Além disso, as transformações urbanísticas do século XX também são marcantes para a história do Mercado e do próprio Bairro de São José. De bairro residencial no início do século passado, São José, gradativamente, adquiriu feições quase que estritamente comerciais, principalmente após a construção da estação rodoviária e da abertura da Avenida Dantas Barreto, na década de 70 (LUBAMBO, 1991).

Seguindo as etapas do projeto, promovemos uma visita à Praça da República- originada por volta do ano de 1639, quando Mauricio de Nassau construiu o primeiro "Jardim Zoobotânico Nacional" (CAVALCANTI, 1998), a qual, de acordo com as leituras empreendidas, abriga marcos históricos e turísticos da cidade do Recife, localizados, atualmente, nas proximidades do Palácio do Campo das Princesas, sede do Governo de Pernambuco e do Teatro Santa Isabel - espaços construídos através dos projetos do Francisco do Rego Barros (Conde da Boa Vista). O primeiro surgiu pela necessidade de um novo edifício para os governadores de Pernambuco. E o segundo foi planejado com base nos trabalhos de profissionais europeus na primeira metade do século XIX, de acordo com o viés de modernização que o Conde da Boa Vista almejava para o Recife (GASPAR, 2009).

${ }^{9}$ Cada grupo integrante do PIBID foi acompanhado pelos professores de História das suas respectivas escolas - o Professor Supervisor. Este é incumbido de direcionar, auxiliar e monitorar as atividades desenvolvidas pelos bolsistas.

Rev. Iberoam. Patrim. Histórico-Educativo, Campinas (SP), v. 5, p. 1-30, e019027, 2019. 
Após o passeio ao antigo jardim zoobotânico, os alunos seguiram à primeira quadra da Praça da República (sentido bairro do Recife- Santo Antônio), na qual se encontra a estátua do Conde da Boa Vista, antigo presidente da Província de Pernambuco, mobilizado à modernização e higienização do Recife. Ao contemplarem a estátua, os alunos foram apresentados à atuação política do conde e ao processo de construção de memória através da articulação entre os lugares visitados já mencionados, as ações empreendidas pelo Conde da Boa Vista e os resultados dos seus projetos.

As análises consistiram na problematização acerca das mudanças arquitetônicas dos espaços que marcam a Praça da República. Apesar da descontinuidade arquitetônica, tanto os prédios, quanto também as estátuas continuam inseridos no contexto histórico da praça e foi importante destacar isso, pois, desde a sua fundação, ela cumpre o papel de centro político-culturaladministrativo do Recife.

A última atividade ocorreu na Avenida Rio Branco, na qual o EREM Porto Digital está localizado, e na Praça Rio Branco - eventualmente conhecida como Marco Zero, pois, instalado pelo Automóvel Clube de Pernambuco, é a partir deste marco que são feitas todas as medidas de distâncias oficiais rodoviárias locais. Neste momento, debatemos como tais espaços resultaram-se da remodelação do bairro do Recife, ocorrida na segunda década do século XX (Recife novo), destacando as mudanças urbanísticas ocorridas na Avenida, quando comparada a existente no século XIX, por meio do alargamento das ruas e da demolição de antigos quarteirões do "Recife velho".

No caso do Marco Zero, sua remodelação decorreu da destruição de diversos espaços, uma vez que metade da atual praça era ocupada por velhos edifícios, e essas reformas atenderam às demandas de diferentes grupos sociais do Recife, excluindo e deslocando outros. Ou seja, a partir de transformações urbanas, existiu uma segregação social no bairro em questão (LUBAMBO, 1991).

Levando em consideração essas intervenções, que modificaram drasticamente fisionomia e a estrutura social do Recife, durante a atividade de campo, destacamos aspectos contemporâneos da praça, como por exemplo, a estátua do Barão de Rio Branco e a um novo empreendimento que começou a fazer parte dessa localidade por volta do ano de 2000 que se chamava "Eu Vi o Mundo e Ele Começava no Recife", projetada pelo pintor Cícero Dias, que visou a revitalização da área do Marco Zero, bem como reestruturação de pontos turísticos e econômicos do bairro, como a Rosa

Rev. Iberoam. Patrim. Histórico-Educativo, Campinas (SP), v. 5, p. 1-30, e019027, 2019. 
dos Ventos, no centro, e o Cais do Porto do Recife, respectivamente (LUBAMBO, 1991; CAVALVANTI; CAVALCANTI, 2010).

Para finalizar, acrescentamos ao processo da observação e reflexão sobre os espaços já mencionados e os seus entornos, com o objetivo de enfatizar o dia a dia das pessoas que frequentam e vivem nesses espaços, solicitamos que os estudantes fizessem até três fotografias, com suas respectivas legendas, que mostrassem de diferentes formas, a importância do reconhecimento e valorização dos patrimônios estudados. Estas fotografias (acompanhadas das suas legendas) foram expostas, juntamente com um rico material iconográfico referente à cidade do Recife - cedido pela Fundação Joaquim Nabuco - para toda comunidade escolar. Além das imagens, os estudantes também produziram (e apresentaram) dois vídeos de curta metragem relacionados as atividades desenvolvidas ${ }^{10}$.

\section{O desenvolvimento do projeto "Tecelões da memória operária: a história de paulista didatizada" - EREM Paulista}

A Escola Estadual do Paulista (atual EREM Paulista) localizada na cidade do Paulista, região metropolitana do Recife, possui turmas dos $1^{\circ}, 2^{\circ}$ e $3^{\circ}$ anos do Ensino Médio, totalizando 1090 alunos matriculados e 43 professores ${ }^{11}$. A maioria dos estudantes mora nos bairros vizinhos e desconheciam a história da cidade do Paulista - isto pode ser explicado não só pela falta de atividades que abordassem o tema na escola, como também pela escassez de materiais informacionais a este respeito.

As atividades foram divididas, inicialmente, em aulas expositivas e, posteriormente, no trabalho de campo. Por último, elaboramos um mural com fotos da Cidade, que ficou exposto para toda comunidade escolar ${ }^{12}$.

As primeiras aulas do projeto de intervenção consistiram em momentos de exposições e diálogos, por intermédio de debates relacionadas não apenas à importância da Educação

10 Vídeos disponíveis através do seguinte link: https://www.youtube.com/watch?v=LroJXT35p8A\&t=98s.

${ }^{11}$ Dados atualizados pelo portal SIEPE. Disponível: http://www.siepe.educacao.pe.gov.br/MapaCoordenadoria/detEscola.do?codUnidade=605935. Acesso em: 07 jun. 2019.

12 As etapas destas atividades encontram-se detalhadas em: TRISTÃO, I. N. N.; OLIVEIRA, C. L.; SANTOS, K. A. B. L. Tecendo a memória operária. In: X Encontro Regional Nordeste de História Oral, 2015, Salvador. Anais eletrônicos, 2015.

Rev. Iberoam. Patrim. Histórico-Educativo, Campinas (SP), v. 5, p. 1-30, e019027, 2019. 
Patrimonial e da História Local, apontando algumas metodologias que auxiliam no processo de construção da história (História oral, análise de imagens, de documentos pessoais, entre outros). Para elaboração das aulas relacionadas à História do Paulista, usamos as referências bibliográficas de José Sergio Leite Lopes (1988) e Rosilene Alvim (1997), que se apresentam em meio a uma escassez de referências sobre a temática estudada.

Os autores supraditos, abordaram a História do Paulista utilizando metodologia da História Oral como fonte histórica. Trabalharam com entrevistas realizadas com ex-operários da Companhia de Tecidos Paulista ${ }^{13}$, pertencente à Família Lundgren, no início do século XX, com fins em perceber as relações desiguais entre patrões e operários, apontando os tipos de dominação que foram identificadas. Mais especificamente, as estratégias de dominação material, simbólica e ideológica do patronato em relação à classe trabalhadora, através dos subsídios da Companhia de Tecidos Paulista (LOPES, 1988).

De posse da bibliografia, durante as aulas, analisamos as relações que se estabeleceram através do desenvolvimento da Fábrica na Cidade, apontando o controle político, social e econômico que a Família Lundgren exerceu sobre Paulista, uma vez que a História da cidade está inteiramente ligada a expansão da indústria têxtil com a CTP, denominado por Lopes (1988) como "sistema Paulista"- conjunto de situações, práticas e "benefícios" que permitiram um maior controle da Fábrica e dos seus entornos na Cidade.

Lopes (1988) denomina a Cidade do Paulista como a "cidade das chaminés", variante da forma de dominação fábrica-vila operária que foi estudada e os Lundgres, por sua vez, foram responsáveis pela construção de igrejas, vilas operárias, praças, etc. e durante muitos anos foram considerados como os "donos" do Paulista. Além disso, possuem, atualmente, um casarão inacessível no centro da cidade: o casarão dos Lundgrens.

Participaram do projeto 25 alunos dos primeiros e terceiros anos do Ensino Médio e os encontros iniciais aconteceram, na maioria das vezes, nos horários das aulas. Apesar de não ter sido uma atividade obrigatória, os estudantes se deslocaram para o acompanhamento das aulas promovidas pelo PIBID.

\footnotetext{
${ }^{13}$ De acordo com o autor, "tanto as entrevistas "históricas" de antigos operários da CTP, ou acontecimentos que marcaram sua história de vida, quanto esta documentação escrita já obtida, chamaram-no atenção para a viabilidade de completar lacunas dos dados obtidos “em campo" com um trabalho historiográfico em arquivos públicos, coleções de jornais e arquivos da própria CTP” (LOPES, 1988, p. 27).
}

Rev. Iberoam. Patrim. Histórico-Educativo, Campinas (SP), v. 5, p. 1-30, e019027, 2019. 
Após as aulas sobre a História do Paulista e as suas relações com o desenvolvimento da Companhia de Tecidos Paulista - Século XX- houve um encontro com os estudantes para identificarmos em conjunto, e com base nas bibliografias levantadas, os lugares que consideravam significativos e importantes dentro da cidade na atualidade. Este momento foi fundamental para o planejamento e execução das atividades de campo, pois, com base nas considerações feitas pelos estudantes ativos no projeto, tivemos a percepção que, após as aulas já mencionadas, esses alunos estariam situados e familiarizados com a História de lugares não analisados por esses sujeitos.

Finalizadas as etapas já mencionadas, partimos para as "aulas de campo". Naquele momento foi realizada uma trilha pela cidade que, com base nas discussões empreendidas, aconteceu através da visita aos seguintes lugares: o casarão dos Lundgrens, a antiga Fábrica de Tecidos Paulista, a feira do centro do Paulista, a Igreja Santa Isabel e a Praça Agamenon Magalhães. Estes espaços, localizados no centro da cidade, também foram mencionados e analisados nas bibliografias levantadas para o planejamento das aulas sobre a História do Paulista e, atualmente, fazem parte do dia a dia não apenas dos estudantes, mas de todas os moradores da cidade.

A atividade em questão só foi possível porque procuramos nos certificar de sua viabilidade ao construirmos uma "pré-trilha". Visitamos os mencionados lugares anteriormente, sem a presença dos estudantes, e fizemos algumas entrevistas "informais" com antigos moradores da cidade para um maior aprofundamento sobre a História da Cidade com base nas vivências e lembranças de diferentes homens e mulheres. Procuramos articular a teoria e a prática, proporcionando aos estudantes sua aproximação com os espaços mencionados e analisados durante as aulas.

Terminadas as aulas iniciais e as atividades de campo, realizamos uma oficina de História Oral. Esta atividade pretendeu familiarizar os estudantes com a metodologia, mostrando como ela pode ser utilizada como fonte histórica e fazendo ligações com os trabalhos historiográficos e etnográficos realizados pela Rosilene Alvim (1997) e José Sérgio Leite Lopes (1988).

Como atividades, realizamos também uma entrevista "formal" de História Oral com uma ex-operária da CTP, Rosália Ferreira, e durante algumas aulas trabalhamos com trechos da transcrição e do áudio, que se encontra disponível no Laboratório de História Oral e da Imagem (LAHOI) da Universidade Federal de Pernambuco.

Rev. Iberoam. Patrim. Histórico-Educativo, Campinas (SP), v. 5, p. 1-30, e019027, 2019. 
Por fim, trabalhando com imagens que foram cedidas por funcionários do Sindicato dos Tecelões do Paulista ${ }^{14}$, localizado no centro da Cidade, elaboramos, em conjunto, um mural iconográfico relacionado a História do Paulista. Este mural ficou exposto para toda comunidade escolar e não apenas as imagens, como também as suas respectivas legendas foram escolhidas pelos próprios estudantes. Ou seja, através das atividades mencionadas, objetivamos que esses alunos percebessem a dinâmica e complexidade das relações sociais por sujeitos que fizeram e fazem parte da História da Cidade, além de conhecer alguns dos lugares antes analisados nas aulas, entender a importância da metodologia da História Oral como fonte histórica e, por último, sintetizar e articular esse conjunto de conhecimentos através da análise e exposição de imagens.

\section{GRUPO FOCAL E OS RELATOS DAS EXPERIÊNCIAS COM EDUCAÇÃO PATRIMONIAL DOS ESTUDANTES DAS EREM PORTO DIGITAL E EREM PAULISTA: APROFUNDANDO O DEBATE}

Com o intuito de nos aproximarmos dos relatos de experiências dos estudantes que participaram dos projetos desenvolvidos pelo PIBID, optamos por trabalhar com a metodologia do grupo focal.

Fazendo um levantamento online sobre esta metodologia nas plataformas do Google Acadêmico, banco de teses de dissertações da CAPES e Repositório Institucional da UFPE, encontramos cerca de 27000 trabalhos relacionados ao tema, sendo a sua maioria relacionados à área de saúde, marketing, publicidade, psicologia da educação e psicopedagogia. No entanto, também tivemos acesso a diversos trabalhos especificamente no campo da educação - música e educação; moda e educação; educação ambiental; educação agrícola; etc. Percebemos que esta metodologia é utilizada por pesquisadoras e pesquisadores das mais diversas áreas de atuação.

Esta metodologia emergiu, inicialmente, nas pesquisas nos campos de saúde e marketing. Foi mencionada, primeiramente, como técnica de pesquisa nos anos de 1920, e introduzida nas

\footnotetext{
${ }^{14}$ Criado na década de 1940, o Sindicato dos Tecelões do Paulista foi resultado de um conjunto de disputas dentro do movimento operário em Paulista. Apesar da movimentação sindical ter começado na cidade a partir do ano de 1910, com o recrutamento de novos trabalhadores para a Companhia de Tecidos Paulista, este órgão só consegue se consolidar de fato quando os Lundgren reduzem as resistências contra as lutas por melhorias dos operários e, desde então, denota um grande alicerce na luta a favor dos empregados fabris.
}

Rev. Iberoam. Patrim. Histórico-Educativo, Campinas (SP), v. 5, p. 1-30, e019027, 2019. 
ciências sociais por R. Nerton, em 1950, com o objetivo de estudar as reações das pessoas à propaganda de guerra (KINALSKI, et al., ${ }^{2017)}$.

O grupo focal consiste em grupo de pessoas selecionadas e reunidas por pesquisadores para discutir e comentar um tema que é objeto de pesquisa a partir da sua experiência pessoal, no nosso caso, a experiência com Educação Patrimonial.

Essa abordagem por grupo é na realidade uma técnica especial de entrevista dirigida a mais de uma pessoa ao mesmo tempo. O principal interesse é que seja criada desse modo uma forma de contexto ou de ambiente social onde o indivíduo pode interagir com o vizinho, deve às vezes defender suas opiniões e pode contestar as dos outros. (LAVILLE, 1999, p. 195)

Após fazer a revisão bibliográfica e estudar as possibilidades que a metodologia com grupo focal pode oferecer, o passo seguinte foi entrar em contato com os alunos que participaram dos projetos anteriormente mencionados. Os convites foram feitos pelas redes sociais dos estudantes e foram muito bem recepcionados. No entanto, nem todos que foram convidados (e aceitaram o convite) puderam participar dos grupos focais, pois, a maior dificuldade, de fato, foi encontrar um horário pertinente para todos.

Em setembro de 2017, realizamos dois grupos focais. O primeiro ocorreu numa sala do Centro de Filosofia e Ciências Humanas, da UFPE, e foi composto por três ex-alunos da EREM Porto Digital. O segundo ocorreu na biblioteca da EREM Paulista, e contamos com seis alunos do terceiro ano do Ensino Médio, respectivamente. Salientamos que os estudantes que participaram das primeiras atividades, em 2014, já concluíram o Ensino Médio, e isso dificultou o contato com a maioria deles para realização da entrevista - o que explica a menor quantidade de entrevistados.

Ressaltamos também que as conversas em grupo não possuíram um viés avaliativo dos estudantes, tomando as respostas por "certas" ou "erradas", mas com a finalidade de nos aproximarmos dos relatos de experiências com Educação Patrimonial nas suas vidas. E, além disso, o anonimato dos estudantes foi preservado não apenas por indicações feitas nos trabalhos que analisamos sobre grupos focais, mas também pelo fato de que estamos lidando com estudantes considerados menores de idade (entre os 16 e 18 anos). Assim sendo, serão identificados de acordo com números, seguidos das iniciais das cidades estudadas (Recife e Paulista), por exemplo: 1R, 2R, 3R; 1P, 2P, 3P, 4P, 5P, 6P. 
O tempo de duração dos dois encontros foi de, aproximadamente, 35 e 40 minutos, respectivamente. O roteiro, anexado a este artigo, das questões norteadoras das discussões em grupo foi dividido por temas e optamos por não trabalhar com perguntas muito objetivas, pois acreditamos que a flexibilidade e as possíveis convergências e divergências entre os entrevistados sejam pontos cruciais tanto no trabalho metodológico com o grupo focal ${ }^{15}$, quanto na ênfase das particularidades das experiências dos estudantes em contato com a Educação Patrimonial.

Em princípio, indagamos os estudantes acerca do PIBID, buscando entender as suas percepções sobre o Programa e as suas opiniões sobre as atuações dos diferentes bolsistas que passaram pelas escolas, bem como dos diferentes projetos que foram desenvolvidos durante o Ensino Médio. Nesta ocasião, percebemos relatos com pontos positivos a respeito do PIBID. As opiniões dos entrevistados não variaram muito e, de acordo com os alunos 1R e 3P:

1R: "Eu acho que o nome em "iniciação à docência" já diz muitas coisas. E também acho legal o fato de que por serem estudantes, vocês tinham uma linguagem mais próxima da gente, de certa forma. E isso tudo aproximou a gente e fez com que a gente pudesse sair da escola e levar o conhecimento junto. Integrar, né?".

3P: "Assim, eu creio que foi gratificante em dois sentidos. Primeiro porque proporcionou a vocês que tão cursando a licenciatura em história ter um contato maior com os alunos e a oportunidade da gente de ter a dinâmica, ter pessoas que estão cursando o curso de história, que não é tão valorizado pela sociedade de maneira geral e tivemos a oportunidade de interagir com isso tudo, né. Então, de maneira geral foi muito gratificante".

O PIBID apresentou aspectos positivos entre os estudantes acima, pois integram docentes e discentes, saberes acadêmicos e saberes escolares, teoria e prática, contribuindo para valorização da História enquanto disciplina escolar.

Quando questionamos sobre as atividades com Educação Patrimonial e História Local, especificamente, percebemos respostas relacionadas à experiência vivida. $\mathrm{O}$ primeiro grupo de estudantes, narraram os lugares "mais marcantes" em suas opiniões e destacaram a importância do trabalho para além do ambiente escolar.

1R: "Eu acho que, tipo, daria até pra falar sem conhecer os lugares. Mas, no geral, a questão da experiência foi a grande chave do PIBID, né? Se a gente desenvolveu, com essa experiência, alguma significação com aquele lugar, com aquele espaço...

15 Para maior aprofundamento sobre esta temática, ler também: GATTI, Bernadete Angelina. Grupo Focal nas pesquisas em Ciências sociais e humanas. Brasília: Líber Livro, 2005.

Rev. Iberoam. Patrim. Histórico-Educativo, Campinas (SP), v. 5, p. 1-30, e019027, 2019. 
muito teve a ver com a oportunidade de estar lá e explorar. Eu acho que a experiência de sair e ir pra "campo" foi o grande ponto".

3R: "Até porque a gente poderia ver os espaços através de fotos, ou quando estivesse indo pra escola e tal... mas essa noção de ir pra explorar a gente só conseguiu depois. Porque antes era uma coisa meio "cega". Você anda assim pelo Recife sem perceber direito os lugares e, tipo, eu simplesmente ia e não parava pra olhar e ver o tanto de coisa que a gente tem e que é tudo muito lindo".

2R: "E, tipo, se tudo isso fosse apresentado pra gente através de imagens ou algum outro recurso virtualizado, acho que não iria despertar tanto interesse na gente. A gente despertou interesse e traz essas lembranças até hoje com a gente porque a gente foi lá e desenvolveu algum tipo de relação com esse espaço".

O segundo grupo entrevistado, por sua vez, também mencionou diferentes questões relacionadas à História da Cidade do Paulista. Perceberam como lugares comuns e corriqueiros adquirem um significado histórico a partir do momento em que são estudados e valorizados.

1P: “Pois é. O PIBID ajudou muito, porque, tipo, é uma coisa que tá aqui tão perto da gente, em Paulista, e eu mesma, por exemplo, nunca tinha parado pra olhar as ruas que eram as vilas dos operários. Daí, depois do PIBID eu fui me informar melhor e descobri que teve família minha que já trabalhou na Fábrica e tal... Eu gostei mais de ver que, na prática, a história foi além dessa história que a gente vinha aprendendo aqui na escola. Não só aquela coisa geral sobre o Brasil ou as guerras, e a gente tinha a história daqui, tão pertinho, do Paulista, e não sabia que era tão rica assim...”.

2P: "Eu passava todo dia naquele casarão, por exemplo, e não sabia quem morava ali... só tinha escutado falar que era dos Lundgren, só isso..."

4P: "É aquela história: nos preocupamos mais com as histórias dos outros do que com a nossa própria história”.

3P: "E teve uma coisa que eu aprendi e sempre guardei foi que Paulista é uma cidade dormitório, sabe? Que as pessoas trabalham fora e só voltam pra dormir... Mas nem sempre foi assim, era uma cidade muito bem desenvolvida, mas em torno da fábrica".

4P: "E outra coisa em relação a vila operária tem também o fato de todas as casas serem iguais, sabe? Que tem a ver com os cargos da Fábrica e o número de pessoas que tinha na família. E até hoje, perto da minha casa, muitas casas ainda são iguais".

Podemos notar que os alunos que participaram das atividades em ambas as escolas, não só estão bem situados nos bairros estudados, como também desenvolveram diversas relações com esses espaços. A partir dos relatos, destacamos as percepções dos estudantes de algumas rupturas 
e continuidades dos "seus" patrimônios, mediante pontes feitas entre o passado e o presente. Concordamos com Horta, Grunberg e Monteiro (1999, p. 17) quando disseram que a Educação Patrimonial provoca situações de aprendizado sobre aspectos culturais, seus produtos e as suas manifestações, de modo que a Cidade se constituiu como um meio ambiente histórico, oferecendo um (re)descobrimento da realidade cultural para a vida desses estudantes. Percebemos que a Educação Patrimonial mostrou-se como uma importante ferramenta de comunicação dos estudantes na medida em que apresentamos uma proposta pedagógica promotora de reflexões e aproximações entre as teorias abordadas em sala de aula e as experiências dos estudantes entrevistados, tornando-os protagonistas e constitutivos da cidade em que vivem.

A importância de entrar em contato com o patrimônio, emergiu posicionamentos dos estudantes sobre a necessidade de projetos dentro desta temática, visto que "é sempre mais fácil e cômodo dar valor e significado ao que está distante de nós, e muitas vezes o que está próximo torna-se invisível e não é digno de ser valorizado e preservado" (TEXEIRA, 2008, p. 203).

Levando em consideração que um dos grandes objetivos da Educação Patrimonial é a preservação, o segundo grupo apontou as seguintes questões:

3P: "O legal daqui do Paulista é que conseguiu preservar a estrutura, a estética mudou, mas boa parte da estrutura ficou preservada".

2P: "Mas a estética, em todos os lugares, com o tempo muda. Não tem como você deixar tudo igual sempre. Até em Olinda mesmo, que é considerada uma cidade histórica, a gente vê que muitas coisas mudaram".

3P: "Mas a parte tombada é preservada, entende? É até mesmo crime mexer naquilo ali. A educação patrimonial é isso: você saber preservar os espaços e os resquícios do passado".

1P: "É tipo um espaço que tá la, claro que o ambiente vai mudar, as pessoas vão mudar... mas, o conjunto, no geral, vai ter que continuar sendo preservado".

4P: "E a questão de restauração também tá até acontecendo aqui no centro do Paulista. Tem a casa dos Lundgren, tem a área que era utilizada pra o lazer dos trabalhadores lá dentro... e tão sempre tentando cuidar, pintar, não deixar ninguém mexer. Mas dizem que vai virar um espaço de turismo".

Foi perceptível nas respostas acima que os estudantes desenvolveram um senso de preservação e um sentimento de apropriação com relação às suas cidades a partir das suas experiências com Educação Patrimonial. Nesse âmbito, salientamos que

Rev. Iberoam. Patrim. Histórico-Educativo, Campinas (SP), v. 5, p. 1-30, e019027, 2019. 
Preservar não é só guardar uma coisa, um objeto ou uma construção, um miolo histórico de uma grande cidade velha. Preservar também é gravar depoimentos, sons, músicas populares e eruditas. Preservar é manter vivos, mesmo que alterados, usos e costumes populares. É fazer, também, levantamentos, levantamentos de qualquer natureza, de sítios variados, de cidades, de bairros, de quarteirões significativos dentro do contexto urbano. É fazer levantamentos de construções, especialmente aquelas sabidamente condenadas ao desaparecimento decorrente da especulação imobiliária. (LEMOS, 1987 p. 29).

Além disso, articulado à perspectiva thompsoniana, na qual a experiência e consciência se relacionam de modo que o cotidiano dos sujeitos está inteiramente ligado a uma criação cultural que abrange os seus modos de vida e as relações sociais (THOMPSON, 1981), defendemos a possibilidade dos estudantes relacionarem suas experiências de vida com as dinâmicas de seus bairros, em diferentes tempos e espaços, na medida em que as ações empreendidas em torno da Educação Patrimonial e da História Local proporcionam um (re) descobrimento de lugares da memória, visto que

Professores e alunos saem da sala de aula e passam a visitar o próprio lugar, os espaços de memória, reler monumentos e ao entrevistar os sujeitos através da dimensão dos temas escolhidos encontram condições para: fazer relações do passado com o presente; decodificar valores da localidade; analisar representações dos sujeitos e seus papeis sobre o vivido; avaliar e substituir representações produzindo novas imagens e modificando o imaginário social. (LUCENA, 1994, p. 127).

Thompson (1981) percebeu, através das lutas e ações dos trabalhadores, a formação de experiências históricas. Para ele, é através das experiências que elaboramos uma explicação racional e lógica das mudanças históricas. Ele considera a experiência como uma consciência histórica, cultural e social.

E é justamente a partir da dimensão educativa do Patrimônio que queremos mostrar, através das análises dos grupos focais, que o uso de fontes patrimoniais no ensino e aprendizagem de História pode desenvolver uma consciência patrimonial e histórica ${ }^{16}$, sendo o espaço urbano percebido e enfatizado como uma ferramenta pedagógica importante não apenas para as aulas de História, mas também, ampliando-se às vivências dos estudantes.

Concordamos com Rocha e Eckert (2007), segundo as quais, o reconhecimento e o estudo das cidades como patrimônios "permitem o conhecimento dos habitantes citadinos de seus

${ }^{16}$ A consciência histórica caracteriza-se através de entendimentos do passado, estruturados de forma narrativa. Ela pode se manifestar através da linguagem oral, objetiva ou como monumentos e símbolos históricos (PINTO, 2011).

Rev. Iberoam. Patrim. Histórico-Educativo, Campinas (SP), v. 5, p. 1-30, e019027, 2019. 
percursos históricos e promovem a consciência do viver social- uma consciência coletiva que não só depende da memória construída, mas contribui para a memória social e coletiva dos cidadãos" (ROCHA; ECKERT, 2007, p. 333). Os estudantes do primeiro grupo, por exemplo, mostraram que seus vínculos com a cidade se construíram por diversas formas. Vejamos:

3R: "Tipo, eu não sei se misturou com a questão anterior, mas, assim, é bem interessante porque ficou marcado nas vidas da gente de forma que até hoje em dia quando a gente vai no Marco Zero, a gente já sabe meio que a História e sempre lembra, né? Por que ali no Paço Alfandega mesmo, sempre que passo ali eu lembro de vocês falando. Enfim, sempre que eu ando por ali, eu lembro, porque independente da escola, é o lugar que sempre vai estar na memória".

1R: "É aquela coisa que Zé sempre repetia inúmeras vezes: a gente pisa na História em duplo sentido, e esquece daquilo que a gente vive, do lugar que a gente passa e da história que ele representa e a gente tá lá, mas muitas vezes não sabe o que ele representa e o seu significado. E poder ter essa dimensão, foi uma coisa que realmente transformou o olhar da gente que foi bem positivo, né? Pessoalmente, eu criei um vínculo que foi além do intelectual, foi um vínculo emocional com a cidade, porque uma das coisas que a gente bateu muito na tecla foi "porque uma pessoa, sem motivação nenhuma, iria depredar uma coisa pública? Um patrimônio?" porque, certamente, não tem vínculo nenhum com aquela representação ou com aquele monumento histórico. $\mathrm{E}$ a partir disso a gente pode dizer que desenvolveu uma relação, no mínimo, emocional com a cidade”.

Levando-se em consideração que um dos objetivos principais da Educação Patrimonial é proporcionar uma compreensão do contexto histórico, cultural e social de diferentes tempos e espaços, enfatizamos também que

É também uma "educação sentimental” naquilo em que pode capacitar os aprendizes a vivenciarem situações diferenciadas, a compreenderem conflitos entre diferentes modos de ver o mundo, a se colocarem "na pele" de outros, cujas histórias eles, até então, ignoravam. (HORTA, 1985, p. 11).

As atividades do PIBID na EREM Paulista coincidiram com um momento muito peculiar: a destruição de alguns resquícios da antiga Fábrica e a construção do primeiro shopping no centro da cidade. Essa situação não apenas causou uma forte mobilização dos estudantes como também ficou explicitamente marcada em suas vidas:

6P: "Eu lembro que teve até toda uma movimentação pra impedir a construção do shopping ali perto de onde era a fábrica, né? Mas quando a gente lembra do lucro que ele tão tendo, logo entende porque foi derrubada".

Rev. Iberoam. Patrim. Histórico-Educativo, Campinas (SP), v. 5, p. 1-30, e019027, 2019. 
4P: "Essas construções de condomínios mesmo, tem no Centro, tem em Jardim Paulista, tem em Mirueira... acabaram com o campo. O campo de Rivaldo tava lá, era quase um ponto turístico de Mirueira... Tem o mercadinho ali perto, os caras jogavam futebol depois iam lá comprar cerveja e comida, no domingo mesmo era muito lotado. Aí eles compraram o terreno, cercaram o campo e tão construindo um prédio. Fora que acabou com a mata toda ali atrás.”.

No decorrer das conversas surgiram questões relacionadas à falta que a Educação Patrimonial pode fazer nas escolas e como ela se mostra necessária para que as pessoas se apropriem, inclusive economicamente, tanto não apenas dos espaços que vivenciam, quanto também da sua História, ou seja, se enxerguem como sujeitos históricos.

3P: "[...] na realidade, nossa sociedade não se interessa muito por isso. Pra o povo pouco importa. Aqui a gente tinha o engenho Maranguape, o engenho Paratibe, e as pessoas nem sabem que existiam. Tão nem aí pra isso. E não ligam por quê? Porque nem todo mundo tem oportunidade de estudar Educação Patrimonial”.

5P: "Pois é, imagina se todo mundo tivesse consciência dessa importância. Por exemplo, imagina se a casa dos Lundgren virasse um museu? Ia gerar empregos, ia dar lucros (que é o que eles querem), ia trazer mais informação, ia atrair pessoas pra saber mais da nossa história...”.

6P: "E seria legal que outras pessoas daqui pudessem ver essas mesmas coisas, que todo ano tivesse um grupo trabalhando com a educação patrimonial também, pra ter sempre continuidade".

Por fim, também destacamos que essas experiências proporcionaram uma ampliação das concepções de preservação e patrimônio por parte dos estudantes e as suas reflexões a respeito de sentimentos, vivências e lembranças.

2R: "Tipo assim, é um conhecimento que você adquire e é igual a ler, você vai levar pra o resto da vida. Não tem como você se abster. E a gente acaba também tendo apreço não só pelas coisas que estão ao nosso redor, ou os monumentos e as estátuas. Tem apreço pelo patrimônio não só no bairro do Recife, mas em outros lugares. Quando a gente escuta notícias de depredamentos de patrimônios de outros lugares aí as pessoas falam "ah, mas não foi daqui não", mas a gente fica ressentida, né? Porque sabe que tudo isso tem um grande valor histórico. Então, tipo, você cria um vínculo não só com o patrimônio, mas também com a história mesmo".

3P: "A gente tem uma riqueza material e histórica muito grande. Com vários outros lugares daqui de Pernambuco dava pra se fazer um trabalho desse tipo. É uma questão não só cultural, mas também de investimento, porque a gente sabe que investir em turismo é uma coisa a longo prazo. É complicado”.

Rev. Iberoam. Patrim. Histórico-Educativo, Campinas (SP), v. 5, p. 1-30, e019027, 2019. 
As relações dos estudantes com os bairros são consideravelmente diferentes. Os alunos da EREM Porto Digital, de forma geral, não são residentes do bairro do Recife - que se configura como um bairro comercial. Os estudantes da EREM Paulista, por outro lado, residem nos entornos da cidade do Paulista.

Os grupos focais realizados em duas escolas diferentes, com perfis de localização e estudantes distintos, aproximaram-se ao reconhecerem a Educação Patrimonial como importante estratégia pedagógica de diálogos, aproximações e transformações nas experiências de vida dos estudantes entrevistados.

A cidade torna-se um objeto privilegiado para a pesquisa histórica na medida em que destaca o papel das experiências sociais como definidoras dos espaços de sociabilidade, nos diversos aspectos de produção do conhecimento histórico e as suas relações com outros espaços e tempos históricos (TOLEDO, 2010).

A partir dos projetos realizados conseguimos promover a ampliação das perspectivas dos estudantes em relação ao meio que os cerca- sua casa, sua escola, seu bairro como patrimônios culturais pertencentes a sua história- e acreditamos que os maiores objetivos e estratégias dentro deste campo são o de fazer com que as pessoas percebam e compreendam o contexto histórico, cultural e social presente em diferentes objetos, artefatos ou lugares, que podem ser preservados nos museus e/ ou fora deles e utilizados como referências para o presente e para o futuro (HORTA, 1985).

\section{CONSIDERAÇÕES FINAIS}

Levando-se em consideração as atividades realizadas no âmbito dos projetos de intervenção do PIBID, nos anos de 2014 e 2015, objetivamos analisar as potencialidades do ensino de História, com foco na educação patrimonial. Para isto, discorremos sobre as políticas que regem os patrimônios no Brasil e como estes se inserem, através dos Parâmetros Curriculares Nacionais, em uma conjuntura de transversalidade e interdisciplinaridade. A Educação Patrimonial e a História Local foram conceituadas e situadas como estratégias que auxiliaram o processo de ensino e aprendizagem de História, além de ampliar os conhecimentos e as concepções acerca dos patrimônios materiais, imateriais e culturais dos bairros nos quais as escolas EREM Porto Digital e EREM Paulista estão localizadas. Articulando teoria e prática, as ações em torno da

Rev. Iberoam. Patrim. Histórico-Educativo, Campinas (SP), v. 5, p. 1-30, e019027, 2019. 
Educação Patrimonial não consistiram em simples visitas aos espaços já mencionados, mas em momentos de avaliações, investigações, descobrimentos e apropriações dos estudantes sobre os seus bairros. Buscamos analisar essas intervenções com base na literatura especializada na temática em questão e com a metodologia do grupo focal e a autonomia das respostas confirmou a recepção positiva do grupo focal como metodologia viável para aproximarmos das experiências vividas, preservando algumas memórias.

Analisando os resultados das atividades desenvolvidas nos anos de 2014 e 2015, tivemos a oportunidade de conversar e entrevistar alguns estudantes que participaram, naquela ocasião, tentando explorar as diferentes memórias e percepções dos mesmos. Salientamos que, de maneira geral, as atividades com Educação Patrimonial geraram um sentimento de pertencimento e uma ampliação de conhecimentos históricos, sociais e culturais sobre os bairros estudados. A partir das análises dos grupos focais, percebemos, nas falas dos estudantes, aspectos positivos relacionados ao PIBID, respostas direcionadas à experiência vivida, a importância de conhecer diferentes espaços através das aulas de campo, como lugares corriqueiros adquirem um significado histórico com as atividades com Educação Patrimonial, as relações que puderam ser desenvolvidas com os espaços estudados, a valorização da Educação Patrimonial (com grande destaque para a falta que esta pode fazer na vida das pessoas) e o reconhecimentos das cidades nas quais as escolas estão inseridas como patrimônios ricos em significados e história.

Para além de compreenderem a importância das atividades em questão, os grupos focais também realçaram um entendimento, apropriação e valorização sobre lugares distintos, ultrapassando as fronteiras dos bairros de Recife e Paulista, fazendo-nos atinar que atividades envolvendo a Educação Patrimonial precisam ser incorporadas nos mais variados espaços escolares, para que surjam novas descobertas e novos trabalhos que ampliem e expandam o assunto. Por outro lado, podemos refletir também sobre possíveis mudanças no currículo de História para que atividades similares possam ser incorporadas efetivamente, além da importância disto tudo na formação das licenciaturas.

\section{REFERÊNCIAS}

ALVIM, Rosilene. A sedução da cidade: os operários-camponeses e a fábrica dos Lundgren. Rio de Janeiro: Graphia Editorial,1997. 
BARBOSA, Vilma de Lurdes. Ensino de História local: redescobrindo sentidos.

Saculum - Revista de História, João Pessoa, jul./dez. 2006.

BRASIL. Parâmetros curriculares nacionais: ensino Fundamental $1^{\circ}$ e $2^{\circ}$ Ciclos - História. Brasília: MEC/SEF, 1997.

BRASIL. Parâmetros curriculares nacionais: ensino Fundamental $3^{\circ}$ e $4^{\circ}$ Ciclos - História. Brasília: MEC/SEF, 1998.

BRASIL. Lei no 9.394/96. Diretrizes e Bases da Educação Nacional. Brasília: Ministério da Educação, 1996.

BRASIL. Orientações curriculares para o ensino médio: conhecimentos de história. Brasília: Ministério da Educação, Secretaria de Educação Básica, 2006.

BRAYNER, Natália Guerra. Patrimônio cultural imaterial: para saber mais. Brasília, DF: IPHAN, 2007.

CABRINI, Conceição et al. O ensino de história: revisão urgente. São Paulo: Brasiliense, 2000.

CARVALHO, Carlos Henrique de. A história local e regional: dimensões possíveis para os estudos histórico-educacionais. Cadernos de História da Educação, no 6, jan./dez. 2007.

CAVALCANTI, Carlos Bezerra. O Recife e seus bairros. Recife: Câmara Municipal do Recife, 1998.

CAVALCANTI, Carlos Bezerra; CAVALCANTI, Vanildo Bezerra. O Recife e suas ruas: se essas ruas fossem minhas. Recife: IAHGP, 2010.

FONSECA, Maria Cecília Londres. Para além da pedra e cal: por uma concepção ampla de patrimônio cultural. In: Memória e Patrimônio: ensaios contemporâneos. Rio de Janeiro: DP\&A, 2003.

FONSECA, Maria Cecília Londres. O patrimônio em processo: trajetória da política federal de preservação no Brasil. Rio de Janeiro: UFRJ/ IPHAN, 1997.

FONSECA, Selva Guimarães. Caminhos da história ensinada. Campinas: Papirus, 1993.

FONSECA, Selva Guimarães. Didática e prática de ensino de história. Campinas: Papirus, 2003.

FREIRE, Eleta C.; RAMOS, Sérgio R. V.; DIONISIO, Ângela P. PIBID UFPE: Por uma nova cultura institucional na formação docente. Recife: Editora Universitária da UFPE, 2014. 
GASPAR, Lúcia. Palácio do governo de Pernambuco. Pesquisa Escolar Online, Fundação Joaquim Nabuco, Recife. 2009. Disponível em: http://basilio.fundaj.gov.br/pesquisaescolar/. Acesso em: 14 nov. 2017.

GASPAR, Lúcia. Teatro Santa Isabel. Pesquisa Escolar Online, Fundação Joaquim Nabuco, Recife. 2009. Disponível em: http://basilio.fundaj.gov.br/pesquisaescolar/. Acesso em: 14 nov. 2017.

GATTI, Bernardete Angelina. Grupo focal na pesquisa em Ciências sociais e humanas. Brasília: Líber Livro 2005.

GONDIM, S. M. G. Grupos focais como técnica de investigação qualitativa: desafios metodológicos. São Paulo: Paidéia, 2003. p. 149-161.

GUILLEN, Isabel C. M.; GRILLO, Maria Ângela F.; FARIAS, Rosilene Gomes. Mercado de São José: memória e história. Recife: FADURPE, 2010.

GRUNBERG, Evelina. Manual de atividades práticas de educação patrimonial. Brasília: IPHAN, 2007.

HORTA, Maria de Lourdes Parreiras. Lições das coisas: o enigma e o desafio da Educação Patrimonial. Boletim do Programa Nacional de Museus, Fundação Nacional Pró-Memória, S. $1,1985$.

HORTA, Maria de Lourdes Parreiras. Fundamentos da Educação Patrimonial. Ciência \& Letras, Porto Alegre: FAPA, nº 27, p. 13-35, 2000.

HORTA, Maria de Lourdes Parreira; GRUNBERG, Evelina; MONTEIRO, Adriane Queiroz. Guia Básico de Educação Patrimonial. Brasília: IPHAN/ Museu Imperial, 1999.

KINALSKI, Daniela D. F. et al. Focus group on qualitative research: experience report. Revista Brasileira de Enfermagem, Brasília, v. 70, n. 2, p. 424-429, mar./abr. 2017.

LAVILLE, Christian. A construção do saber: manual de metodologia da pesquisa em ciências humanas. Porto Alegre: Artmed; Belo Horizonte: UFMG, 1999.

LEMOS, Carlos A .C. O Que é patrimônio histórico. São Paulo, Brasiliense, 1987.

LE GOFF, Jacques. História e memória. 7. ed. Revista. Campinas, SP: Editora da UNICAMP, 2013.

LOPES, José Sérgio Leite. A Tecelagem dos conflitos de classe na "Cidade das Chaminés". São Paulo: Editora UnB, 1988.

LUBAMBO, Catia W. O Bairro do Recife: entre o corpo santo e o marco zero. Recife: Fundação Cidade e Cultura do Recife, 1991. 
MAUAD, Ana Maria. Através da imagem: fotografia e história interfaces. Tempo, Rio de Janeiro, v. 1, no 2, p. 73-98, 1996.

PINTO, Maria Helena M. N. F. Educação histórica e patrimonial: concepções de alunos e professores sobre o passado em espaços do presente. 2011. 427f. Tese (Doutorado) -

Universidade do Minho, Instituto de Educação, 2011.

POLLAK, Michel. Memória e identidade social. Estudos históricos, Rio de Janeiro, v. 5, nº 10, p. 200-212, 1992.

ROCHA, Ana Luiza Carvalho da; ECKERT, Cornelia. A cidade: sede de sentidos. In: LIMA FILHO, Manuel Ferreira; BELTRÃO, Jane Felipe; ECKERT, Cornelia (Orgs). Antropologia e patrimônio cultural: diálogos e desafios contemporâneos. Blumenau: Nova Letra, 2007

SAMUEL, Raphael. História local e História oral. Revista Brasileira de História, v. 9, nº 19. São Paulo: ANPUH/ Marco zero, p. 219-243, set. 1989.

SOARES, André L. R.. Dr. Jeckyl and Mister Hide ou “A educação patrimonial serve a quem?”. In: MAGALHÃES, Leandro Henrique; ZANON, Elisa Roberta; BRANCO, Patrícia Martins Castelo (Org.). A Construção de Políticas Patrimoniais: ações preservacionistas de Londrina, Região Norte do Paraná e Sul do País. Londrina: UniFil, 2009. p. 19-34. V. 1.

SCHIAVON, Carmen G. B.; SANTOS, Tiago F. Educação Patrimonial: um caminho à discussão sobre a cidadania a partir da história local. Udesc em Ação, v. 5, p. 01-10, 2011.

TEIXEIRA, Cláudia A. R. A Educação Patrimonial no Ensino de História. Biblos (Rio Grande), v. 22, n. 1, p. 199-211, 2008.

TOLEDO, Maria Aparecida L. T.. História local, historiografia e ensino: sobre as relações entre teoria e metodologia do ensino de História. Antíteses (Londrina), v. 3, p. 1-16, 2010.

TRISTÃO, Isabela; SILVA, Adriana M. P. História Local e Educação Patrimonial: a experiência do PIBID na Escola Estadual do Paulista. Educação Básica Revista, v. 4, p. 83-93, 2018.

THOMPSON, Edward P. O termo ausente: experiência. In: A miséria da teoria. Rio de Janeiro, Zahar, 1981.

Recebido em: 07 de junho de 2019 Aceito em: 01 de novembro de 2019

Rev. Iberoam. Patrim. Histórico-Educativo, Campinas (SP), v. 5, p. 1-30, e019027, 2019. 